\title{
Association between Health-Related Physical Fitness and Respiratory Diseases in Adolescents: An Age- and Gender-Matched Study
}

\author{
Jeong-Hui Park ${ }^{1}{ }^{(}$, Myong-Won Seo ${ }^{2} \mathbb{D}$, Hyun Chul Jung ${ }^{3 \oplus}$, Jong-Kook Song ${ }^{2}$ and Jung-Min Lee ${ }^{1,4, * \mathbb{C}}$ \\ 1 Department of Physical Education, Kyung Hee University (Global Campus), 1732 Deokyoungdaero, \\ Giheung-gu, Yongin-si 17014, Gyeonggi-do, Korea; jeonghee@khu.ac.kr \\ 2 Department of Taekwondo, Kyung Hee University (Global CAMPUS), 1732 Deokyoungdaero, Giheung-gu, \\ Yongin-si 17014, Gyeonggi-do, Korea; myongwonseo@khu.ac.kr (M.-W.S.); jksong@khu.ac.kr (J.-K.S.) \\ 3 Department of Coaching, Kyung Hee University (Global Campus), 1732 Deokyoungdaero, Giheung-gu, \\ Yongin-si 17014, Gyeonggi-do, Korea; jhc@khu.ac.kr \\ 4 Sports Science Research Center, Kyung Hee University (Global Campus), 1732 Deokyoungdaero, Giheung-gu, \\ Yongin-si 17014, Gyeonggi-do, Korea \\ * Correspondence: jungminlee@khu.ac.kr
}

check for

updates

Citation: Park, J.-H.; Seo, M.-W.; Jung, H.C.; Song, J.-K.; Lee, J.-M. Association between Health-Related Physical Fitness and Respiratory Diseases in Adolescents: An Age- and Gender-Matched Study. Int. J. Environ. Res. Public Health 2021, 18, 6655. https://doi.org/10.3390/ ijerph18126655

Academic Editor: Paul B. Tchounwou

Received: 23 May 2021

Accepted: 19 June 2021

Published: 21 June 2021

Publisher's Note: MDPI stays neutral with regard to jurisdictional claims in published maps and institutional affiliations.

Copyright: (c) 2021 by the authors. Licensee MDPI, Basel, Switzerland. This article is an open access article distributed under the terms and conditions of the Creative Commons Attribution (CC BY) license (https:/ / creativecommons.org/licenses/by/ $4.0 /)$.
Abstract: The current study examined the differences in health-related physical fitness (HRPF), physical activity (PA), and sedentary behavior (SB) between adolescents with and without ongoing respiratory diseases (RD). This study's participants were from 12 to 15 years old (7th-10th grade) in South Korea. Adolescents with RD were selected through RD-related questions (i.e., asthma, rhinitis, sinusitis, and bronchitis) ( $n=139)$; in contrast, adolescents without RD, randomly selected from the general group, responded to any health problem-related questions as "No" $(n=139)$. HRPF was measured based on the FITNESSGRAM and EURO FIT test batteries and the measurements of HRPF included cardiovascular endurance, muscular strength, muscular endurance, flexibility, and body composition. All statistical analyses were conducted by SPSS 25.0, and the independent $t$-test was used to compare the HRPF and PA between the two groups. Moreover, the measured HRPF was compared with a series of analyses of three-way ANOVAs (age $\times$ gender $\times$ group). Adolescents with RD had a positive association with less participation in PA $(p<0.05$; RD: $3081.81 \pm 4793.37$; general: $2073.64 \pm 3123.47$ ) and with more time spent on SB (above $12 \mathrm{~h}$ per week: RD group (38.85\%) and general group (33.09\%)). Furthermore, adolescents in the RD group showed significant effects on all components of HRPF ( $p<0.05$ ). Our study confirmed that HRPF is an essential predictor of adolescents' health outcomes, especially for those with RD. We suggest that increased HRPF can be an effective treatment for respiratory diseases in adolescents, and health practitioners should pay more attention to helping adolescents with RD to gain or maintain high HRPF.

Keywords: physical fitness; respiratory diseases; physical activity; sedentary behavior; adolescents

\section{Introduction}

Adolescence is a preliminary stage in preparing for an adult's role, which involves undergoing various changes, such as physical, psychological, and social development processes. Therefore, adolescence is when significant health-related behaviors are determined [1]. In particular, health-related physical fitness (HRPF) has been identified as a crucial predictor of health outcomes in adolescence, as well as in adulthood [2,3]. The components of physical fitness, including cardiovascular endurance, muscular strength and endurance, flexibility, and body composition, are associated with risk factors of cardiovascular diseases and musculoskeletal health [4-6]. Improvement in HRPF during school age and adolescence is important for maintaining a healthy lifestyle in adulthood. For instance, adolescents with low HRPF more likely to be overweight and obese rather 
than those with high levels of HRPF [7] and this unfavorable condition links to obesity in adulthood, which results in adverse health outcomes in later life $[8,9]$.

Additionally, some studies have reported that there is a strong association between HRPF and physical activity (PA) $[10,11]$. One study examined the correlation between HRPF and PA in adolescents and the results indicated that there are obvious interconnections between HRPF and moderate-to-vigorous physical activity (MVPA), and adequate HRPF for adolescents could be derived from sufficient MVPA [12]. Pedro and colleagues' study demonstrated that adolescents' HRPF is not only associated with MVPA, but also sedentary behavior (SB), so promoting MVPA and reducing prolonged SB should be considered first to improve HRPF [13]. Therefore, adolescents' HRPF, PA, and SB are closely related by their underlying causal factors and should be considered together when their health is measured.

Despite accumulated scientific evidence on the importance of HRPF and PA in adolescents, their HRPF and PA have been declining annually over the past decade [14], and similarly, this finding is consistent with Asian adolescents' HRPF and PA studies [15-17]. Poor HRPF and low participation in PA has eventually led to an increase in the prevalence of obesity and respiratory diseases (RD) (i.e., asthma, rhinitis, and sinusitis) because of exacerbation of the pulmonary function $[18,19]$. Specifically, typical RD includes asthma and rhinitis, and asthma is known as a chronic lower RD with various symptoms such as hypersensitivity of the airway, phlegmatic cough, and chest compressions [20]. Moreover, rhinitis is an upper RD with symptoms such as itching, runny nose, and sneezing [21], and the symptoms are closely correlated with other RDs, such as sinusitis and bronchitis [22,23].

According to the International Study of Asthma and Allergies in Childhood (ISAAC), the number of adolescents with RD has increased and this phenomenon is expected to gradually increase with an additional 400 million adolescents with RD by 2025 [24,25]. Although there is little doubt that the cause of the increased prevalence of RD is multifactorial (i.e., environment, air pollution, and genetics) [26,27], there is a growing body of literature that implicates lifestyle changes, specifically decreased PA and HRPF, as being a strong contributor to the increase in $\mathrm{RD}$ [28-30]. As an extension of the aforementioned studies, a recent study conducted by Park and colleagues reported that adolescents with $\mathrm{RD}$ participate less in PA and maintain SB longer than those who without RD, and they also have a higher BMI than general adolescents [31].

The overwhelming majority of studies have demonstrated that increasing HRPF, engaging in regular PA, and reducing $\mathrm{SB}$ has the major health benefit of alleviating RD, but there has not yet been an empirical investigation into different HRPF, PA, and SB levels of adolescents with ongoing RD compared to general adolescents. Therefore, the primary aim of the study was to investigate the differences in HRPF, PA, and SB between adolescents with and without ongoing RD. Additionally, the secondary aim was to examine the impacts of RD on HRPF, PA, and SB among different ages and genders in comparison to general adolescents.

\section{Methods}

\subsection{Design}

The participants were recruited from each city in South Korea using stratified sampling procedures based on the geographic regions, school districts, school type, and gender distribution of each city. Specifically, one or more school districts were selected within each city. Data from 1686 adolescents were collected and all participants aged 12-15 years (7th-10th grade) with a health status that allowed participation in physical fitness tests were eligible.

\subsection{Study Participants}

One thousand six hundred and eighty-six Korean adolescents participated in the HRPF test and responded to the questionnaire in the current study. Among these, adolescents with $\mathrm{RD}$ were selected through health-related questions (health assessment survey questions), 
and all adolescents with RD were matched for age and gender with adolescents without RD. Adolescents in the RD group $(n=139)$ either answered the asthma-related questions (i.e., "Are you currently suffering from asthma?" / Have you ever been to a hospital because of asthma?") with "Yes" ( $n=85)$ or reported that they had other RDs besides asthma (i.e., rhinitis, sinusitis, and bronchitis) $(n=54)$. In contrast, adolescents, randomly selected to the general group, responded to any health problem-related questions such as above with "No" $(n=139)$. Before the study, we provided a complete written explanation regarding the study's purpose, procedure, and possible occurrence of discomfort and risks, and we received written informed consent from each participant's parent or legal guardian. All participants were aware that they could withdraw at any time without any prejudice. This study was approved by the Institutional Review Board (IRB) of Mahidol University (MU-IRB2014/029.1302).

\subsection{Measures}

\subsubsection{Health-Related Physical Fitness (HRPF)}

HRPF was measured based on the FITNESSGRAM [32] and EURO FIT [33] test batteries, both of which have demonstrated good reliability and validity for use in adults, as well as adolescents $[34,35]$. The measurements of HRPF included cardiovascular endurance, muscular strength, muscular endurance, flexibility, and body composition, and the entire testing process was conducted under the supervision of well-trained assistants. (1) Cardiovascular endurance was evaluated using a $15 \mathrm{~m}$ progressive aerobic cardiovascular endurance run (15 m PACER) and was performed once. The $15 \mathrm{~m}$ PACER is an alternative way to measure cardiovascular endurance and an easy-to-measure for a limited gymnasium, as evidence suggests that it provides a similar profile of the adolescent's cardiovascular endurance compared to the $20 \mathrm{~m}$ PACER [36]. (2) Muscular endurance was evaluated through a $1 \mathrm{~min}$ sit-up test and performed once. (3) Muscular strength was evaluated using a hand-grip strength dynamometer with accuracy to the nearest $0.1 \mathrm{~kg}$ (Takei Scientific Instruments Co. Ltd., T.K.K. 5101 Grip D, Tokyo, Japan). The measurements, left-hand and right-hand grip strength, were taken two times and the average score was calculated. (4) Flexibility was measured using an Acuflex I modified flexibility sit-and-reach test box (PSYMTEC, Madrid, Spain). As muscular strength measurements, the sit-and-reach test was also measured two times for the left and the right leg, and the average scores were calculated from the measured test scores. (5) Body composition was measured by biometric impedance analysis (BIA, Tanita, TBF-543, Japan), and height (SECA S-208M, the United States) and weight (TANITA, BC-581, Japan) were measured directly. Additionally, body mass index (BMI) was calculated by dividing the weight $(\mathrm{kg})$ by the square of the height $\left(\mathrm{m}^{2}\right)$.

\subsubsection{Self-Reported Physical Activity (PA)}

Self-reported PA was measured using the International Physical Activity QuestionnaireShort Form (IPAQ-SF) and the Korean version of the IPAQ-SF has demonstrated high reliability and validity [37]. All participants reported frequency (i.e., days), duration (i.e., minutes), and intensity (i.e., moderate and vigorous) of their participation in PA over the past seven days. PA was calculated by "metabolic equivalent task (MET) level $\times$ minutes $\times$ number of days per week" for each intensity, with 4.0 METs for moderate physical activities and 8.0 METs for vigorous physical activities. Meanwhile, moderate-to-vigorous-intensity PA was calculated by the sum of METs calculated from moderate- and vigorous-intensity PA per week.

\subsubsection{Self-Reported Sedentary Behavior (SB)}

Self-reported SB was estimated by the interviewer-administered Adolescent Sedentary Activity Questionnaire [38], and the participants were asked how many hours they sit for study and leisure time during a week. SB included sitting time in their house, school, 
and private institute, and SB for leisure included any sedentary time spent, for example, watching TV or playing video and online games, except for studying.

\subsection{Statistical Analysis}

The demographic information (i.e., gender, age, height, and weight) and SB of the participants were summarized by descriptive statistics in SPSS version 25.0 (IBM, Chicago, IL, USA). The independent $t$-test was used to compare the HRPF (i.e., cardiovascular endurance, muscular endurance, muscular strength, flexibility, and body composition) and PA between the two groups. Furthermore, the measured HRPF was compared with a series of analyses of three-way ANOVAs (age $\times$ gender $\times$ group), and post-hoc analysis was performed using Bonferroni's correction among age, gender, and groups. Cohens' $d$ (small $\geq 0.2$, medium $\geq 0.5$, and large $\geq 0.8$ ) was used to assess the standardized difference in PA, SB, and HRPF between the RD and general groups. The least-squares means and standard errors were estimated within the model and the overall effects were examined with the standard F-test.

\section{Results}

The demographic characteristics and anthropometric measurements (i.e., height, weight, and BMI) were analyzed by descriptive statistics as frequencies and proportions (Table 1). A total of 278 adolescents participated in the present study and the mean of ages for both groups (i.e., general and RD groups) was 13.38 years; males comprised $60.43 \%$ and females $39.57 \%$ of the sample. The adolescents' characteristics (i.e., gender and age) indicated no significant differences between the two groups, because age and gender were matched. No anthropometric measurements (i.e., height, weight, and BMI) showed significant differences between the two groups.

Table 1. Characteristics and anthropometrics of the participants.

\begin{tabular}{|c|c|c|c|c|c|}
\hline \multirow{2}{*}{\multicolumn{2}{|c|}{ Variable }} & \multicolumn{2}{|c|}{ General $(n=139)$} & \multicolumn{2}{|c|}{$\mathrm{RD}(n=139)$} \\
\hline & & No. (\%) & Mean \pm SD & No. (\%) & Mean \pm SD \\
\hline \multirow{2}{*}{ Gender } & Boys & $84(60.43)$ & & $84(60.43)$ & \\
\hline & Girls & $55(39.57)$ & & $55(39.57)$ & \\
\hline \multirow{4}{*}{$\begin{array}{c}\text { Age } \\
\text { (years) }\end{array}$} & 12 & $38(27.34)$ & \multirow{4}{*}{$13.38 \pm 1.06$} & $38(27.34)$ & \\
\hline & 13 & $33(23.74)$ & & $33(23.74)$ & \\
\hline & 14 & 45 (32.37) & & 45 (32.37) & $13.38 \pm 1.06$ \\
\hline & 15 & $23(16.55)$ & & $23(16.55)$ & \\
\hline \multirow{2}{*}{$\begin{array}{l}\text { Height } \\
(\mathrm{cm})\end{array}$} & Boys & & $163.87 \pm 6.88$ & & $163.68 \pm 9.65$ \\
\hline & Girls & & $160.65 \pm 3.81$ & & $157.93 \pm 5.72$ \\
\hline \multirow{2}{*}{$\begin{array}{l}\text { Weight } \\
(\mathrm{kg})\end{array}$} & Boys & & $55.62 \pm 9.21$ & & $57.36 \pm 13.00$ \\
\hline & Girls & & $54.86 \pm 6.67$ & & $53.96 \pm 7.98$ \\
\hline \multirow{2}{*}{$\begin{array}{c}\text { BMI } \\
\left(\mathrm{kg} \cdot \mathrm{m}^{-2}\right)\end{array}$} & Boys & & $20.61 \pm 2.78$ & & $21.20 \pm 3.63$ \\
\hline & Girls & & $21.20 \pm 2.41$ & & $21.55 \pm 2.64$ \\
\hline
\end{tabular}

RD: Respiratory disease, SD: Standard deviation, BMI: Body mass index. There were no significant differences in height, weight, or BMI between the general and RD groups $(p>0.05)$.

The results of adolescents' PA, SB, and HRPF between the general and RD groups are presented in Table 2. Moderate-intensity PA (MPA; $p=0.047$, Cohen's $d=0.23$ ) and MVPA ( $p=0.039$, Cohen's $d=0.24)$ indicated significant differences, but vigorous-intensity PA (VPA) showed no significant differences between the two groups $(p=0.660$, Cohen's $d=0.22$ ). In addition, in $\mathrm{SB}$, adolescents who spent from 6 to $12 \mathrm{~h}$ a week sitting down accounted for a higher percentage of those in the general group (46.04\%) than those with $\mathrm{RD}(41.01 \%)$, while adolescents who spent more than $12 \mathrm{~h}$ a week sitting down accounted for a higher percentage of those in the RD group (38.85\%) rather than those in the general group (33.09\%). According to the results for HRPF presented in Table 2, RD showed significant effects for each of the components of HRPF, including cardiovascular endurance 
$(p<0.001$, Cohen's $d=0.67)$, muscular endurance $(p=0.003$, Cohen's $d=0.35)$, left $/$ right strength (left: $p=0.003$, Cohen's $d=0.35$; right: $p=0.006$, Cohen's $d=0.33$ ), left $/ \mathrm{right}$ flexibility (left: $p=0.003$, Cohen's $d=0.35$; right: $p=0.013$, Cohen's $d=0.29$ ), and body composition $(p=0.038$, Cohen's $d=0.28)$.

Table 2. Participants' physical activity, sedentary behaviors, and health-related physical fitness.

\begin{tabular}{|c|c|c|c|c|c|c|}
\hline & \multirow{2}{*}{ Variable } & \multicolumn{2}{|c|}{ General $(n=139)$} & \multicolumn{2}{|c|}{ RD $(n=139)$} & \multirow{2}{*}{ Cohen's $d$} \\
\hline & & No. (\%) & Mean \pm SD & No. $(\%)$ & Mean \pm SD & \\
\hline \multirow{3}{*}{$\begin{array}{l}\text { Physical } \\
\text { Activity }\end{array}$} & $\begin{array}{l}\text { Moderate-intensity PA } \\
\quad(\mathrm{min} / \text { week })\end{array}$ & & $1003.42 \pm 1828.73$ & & $645.32 \pm 1072.71 *$ & 0.23 \\
\hline & $\begin{array}{l}\text { Vigorous-intensity PA } \\
\text { (min/week) }\end{array}$ & & $2078.39 \pm 3329.86$ & & $1428.32 \pm 2484.39$ & 0.22 \\
\hline & $\begin{array}{l}\text { Moderate-to-vigorous- } \\
\text { intensity PA } \\
\text { (min/week) }\end{array}$ & & $3081.81 \pm 4793.37$ & & $2073.64 \pm 3123.47$ * & 0.24 \\
\hline \multirow{3}{*}{$\begin{array}{l}\text { Sedentary } \\
\text { Behaviors }\end{array}$} & Under $6 \mathrm{~h}$ & $25(17.99)$ & & $25(17.99)$ & & \\
\hline & 6-12 h & $64(46.04)$ & & $57(41.01)$ & & \\
\hline & More than $12 \mathrm{~h}$ & $46(33.09)$ & & $54(38.85)$ & & \\
\hline \multirow{7}{*}{ HRPF } & PACER (laps) & & $51.78 \pm 20.76$ & & $39.01 \pm 16.83^{* * *}$ & 0.67 \\
\hline & Sit-ups (reps/min) & & $40.90 \pm 11.12$ & & $36.93 \pm 11.13^{* *}$ & 0.35 \\
\hline & Grip strength (left, kg) & & $26.24 \pm 4.59$ & & $24.08 \pm 7.31^{* *}$ & 0.35 \\
\hline & Grip strength (right, kg) & & $27.15 \pm 5.17$ & & $25.06 \pm 7.17^{* *}$ & 0.33 \\
\hline & Sit and reach (left, $\mathrm{cm})$ & & $62.22 \pm 11.87$ & & $58.15 \pm 10.85^{* *}$ & 0.35 \\
\hline & Sit and reach (right, cm) & & $61.54 \pm 11.83$ & & $58.09 \pm 11.18 *$ & 0.29 \\
\hline & Body composition (BIA, \%) & & $23.89 \pm 6.43$ & & $25.95 \pm 7.86^{*}$ & 0.28 \\
\hline
\end{tabular}

RD: Respiratory diseases; SD: Standard deviation; HRPF: Health-related physical fitness; BIA: Bioelectrical impedance analysis; PACER: Progressive aerobic cardiovascular endurance run. ${ }^{*} p<0.05,{ }^{* *} p<0.01$, and ${ }^{* * *} p<0.001$.

Figure 1 displays the mixed-model $4 \times 2 \times 2$ (age $\times$ gender $\times$ group) analysis of variance (ANOVA). The interaction of age $\times$ gender $\times$ group was nonsignificant $(p>0.05)$, but there were significant main effects for group $(p<0.05)$ and gender $(p<0.001)$ in the measured HRPF. Moreover, the effects for age were only revealed in left/right hand-grip (left: $p<0.001$; right: $p<0.001)$ and PACER $(p=0.003)$. Bonferroni post-hoc tests revealed nonsignificant pairwise differences between gender, age, and group in the components of HRPF $(p>0.05)$, but left/right hand-grip was significantly different in the two-way interaction for age $\times$ group (left: $p=0.002, F(3,262)=5.147$, partial $\eta^{2}=0.056$; right: $p=0.021$, $F(3,262)=3.289$, partial $\left.\eta^{2}=0.036\right)$. Additionally, there were significant differences in the two-way interaction for age $\times$ gender (left: $p<0.001, F(3,262)=14.673$, partial $\eta^{2}=0.144$; right: $p<0.001, F(3,262)=8.283$, partial $\left.\eta^{2}=0.087\right)$, which yielded a large effect size, and PACER showed a significant difference in the two-way interaction for gender $\times$ group $(p=0.027, F(1,262)=4.918)$. 

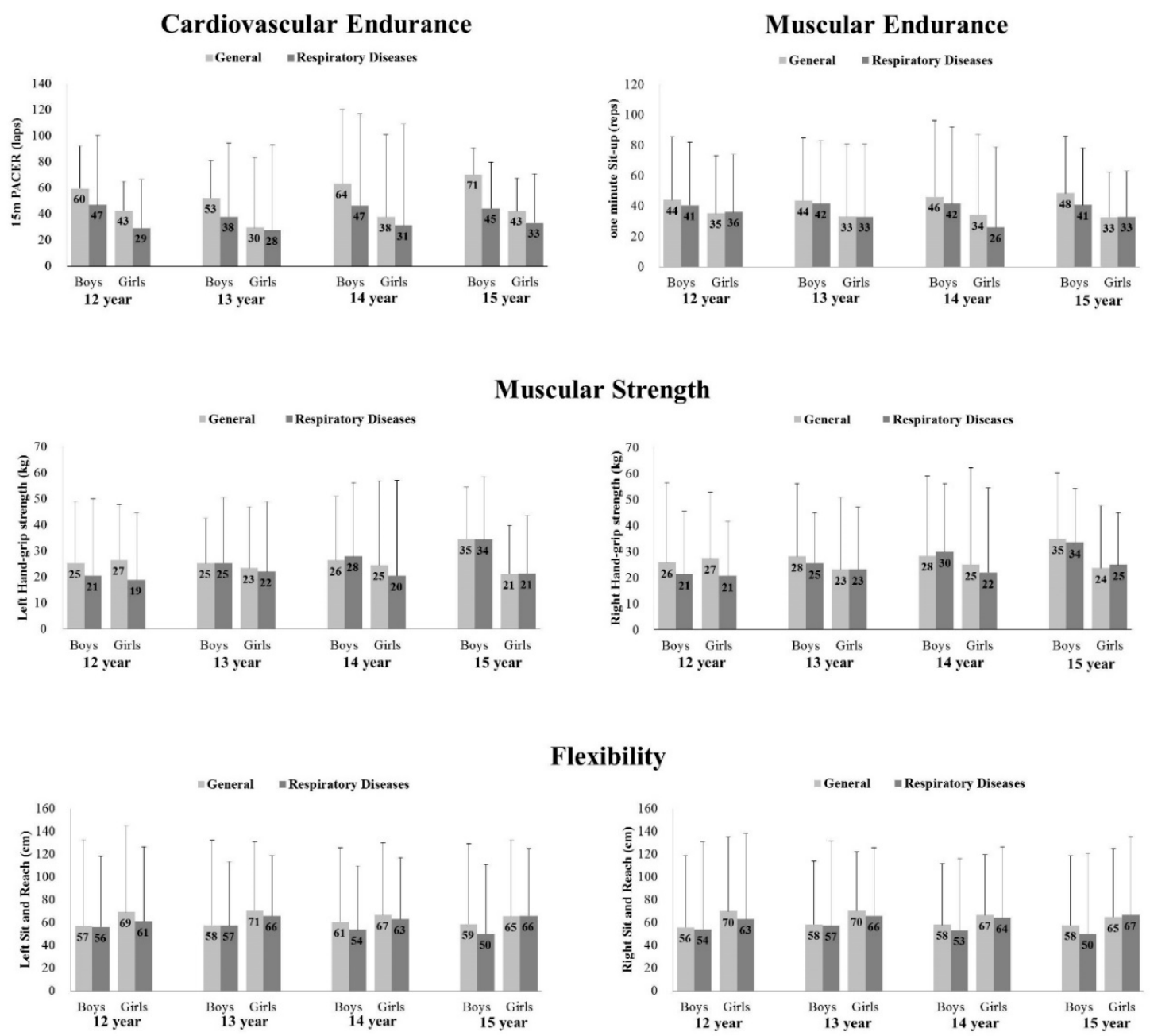

Flexibility

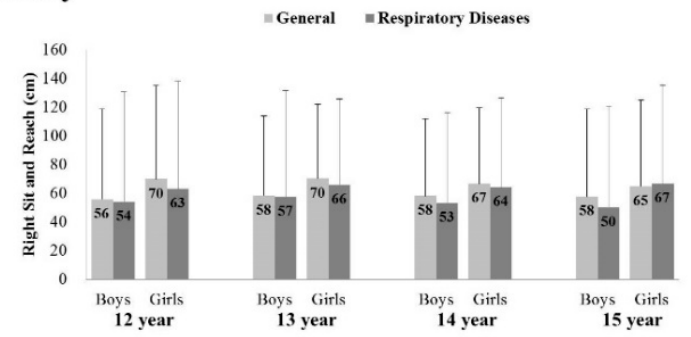

Body Composition

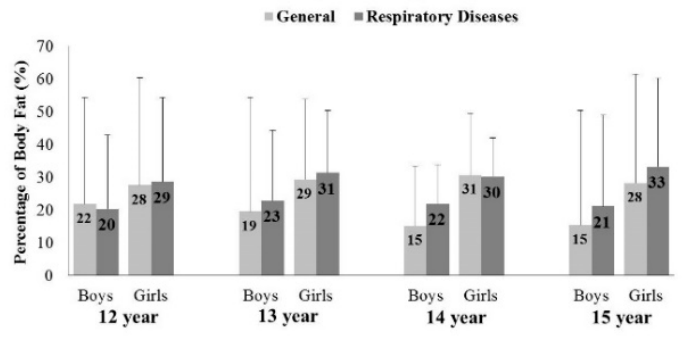

Figure 1. Health-related physical fitness test in aerobic capacity, muscular endurance, muscular strength, muscular flexibility, and body composition. PACER: Progressive aerobic cardiovascular endurance run. The differences in HRPF with their corresponding parameters (i.e., respective standard errors) are presented.

\section{Discussion}

The purpose of this study was to investigate the differences in HRPF, PA, and SB between adolescents with and without ongoing RD. The prevalence of RD in adolescence is uncertain, both in terms of its mechanism and directionality, and it does not have a life-threatening effect [39]. However, RD problems in adolescence are not only highly likely to continue into adulthood, but also have adverse impacts on quality of life, disability, and productivity [40]. Despite many studies that have emphasized the importance of maintaining appropriate PA and fitness to ameliorate RD [41,42], the current evidence on HRPF in adolescents with RD is ambiguous, and some studies have even demonstrated the outcomes measured by only a specific HRPF of adolescents with RD [43,44]. 
This study compared HRPF, PA, and SB, as well as anthropometric information, between adolescents with and without RD. The main findings of the current study were that $\mathrm{RD}$ (i.e., asthma, rhinitis, sinusitis, and bronchitis) in adolescence is positively associated with HRPF (i.e., cardiovascular endurance, muscular endurance, muscular strength, flexibility, and body composition). Although it is difficult to determine any direct relationships between RD and HRPF, our study confirmed that adolescents with RD not only have significantly lower HRPF than general adolescents, but also less participation in PA and more time spent engaging in SB. Therefore, we speculate that adolescents with RD have a robust association with lower HRPF, less participation in PA, and more time spent engaging in SB.

Specifically, it is worth noting that adolescents with RD had a relatively higher BMI than general adolescents. Although anthropometric information such as body weight and BMI were not significantly different between the two groups, average BMI was higher for both boys and girls in the RD group than those in the general group. Our results are consistent with previous studies [31,45,46], which serve as an opportunity to empower the results of prior studies. Furthermore, the RD group's adolescents who showed a high BMI participated in significantly lower MVPA $(p<0.05)$ and spent more than $12 \mathrm{~h}$ a week sitting down rather than the general group's adolescents (general: 33.09\%; RD: 38.85\%). We assume that lower MVPA and more time spent engaging in SB could potentially contribute to the high BMI in adolescents with RD [47]. Most adolescents with RD are known to suffer from uncontrolled and burdensome symptoms caused by RD such as rhinorrhea, sneezing, postnasal drip, daytime fatigue, and sleep disturbance that directly interfere with their daily lives $[48,49]$. These symptoms reduce quality of life and sustain extreme stress [50], which may have affected the low participation in PA and the increased time spent engaging in $\mathrm{SB}$ in adolescents with ongoing RD.

Our study provides novel findings regarding the association between HRPF and RD, cardiovascular endurance, and muscular strength specifically. The PACER test is a wellestablished indicator of cardiovascular endurance, and this component has been associated with body composition, as well as the risk of all-cause mortality, metabolic diseases, and cardiovascular diseases [51,52]. Meanwhile, muscular strength (i.e., hand-grip strength) is also known as a major risk factor for coronary heart disease, stroke, suicide, and even cancer [53-55]. Despite the outcomes of many prior studies, the level of cardiovascular endurance and grip strength of adolescents with RD were significantly lower than those of general adolescents $(p<0.001$ and $p<0.01$, respectively), and its outcomes are consistent with Latorre-Román's findings that demonstrated an association with levels of RD severity and muscular strength [56]. The reason could be because adolescents with RD may still have concerns about exacerbation of their RD during any participation in PA. Since low HRPF has a multifactorial cause (i.e., age, gender, and nutritional status), it cannot be determined whether promoting PA is the only factor that can overcome low HRPF, but increasing participation in regular PA and reducing SB seems to be an effective way to improve their HRPF and prevent other diseases that can be caused by low HRPF [57].

The present study has the following positive strengths and limitations. To the best of our knowledge, no other studies have directly measured the HRPF of adolescents with RD or have compared HRPF between adolescents with and without RD. Furthermore, the main findings of this study add to the existing literature on the association between RD and adolescents' health-related behaviors (i.e., MVPA, SB, and body weight status) and also provide new insights regarding the factors contributing to RD, such as HRPF and PA. However, since this study did not consider the severity of respiratory diseases, future studies need to scrutinize how the severity of respiratory diseases affects HRPF. Additionally, the participants in this study were limited to Korean adolescents. Therefore, it is necessary to examine more evidence with various ethnicities and adequate sample sizes from the same perspective. 


\section{Conclusions}

This study investigated the association between HRPF, PA, and SB, comparing adolescents with RD to those without. The results support that adolescents with RD engage less in PA and spend more time in SB than general adolescents, and is has been evidently confirmed that HRPF is an essential predictor of adolescents' health outcomes-especially for those with RD. The strategy that can be pursued through this study is brief but exciting, and increased HRPF could be an effective treatment for respiratory diseases in adolescents. Therefore, we suggest that health practitioners should pay more attention to helping adolescents with RD gain or maintain high HRPF, and recommended HRPF guideline for adolescents with RD should be specifically developed.

Author Contributions: Data curation, J.-H.P. and J.-M.L.; formal analysis, J.-H.P. and J.-M.L.; investigation, M.-W.S., H.C.J., and J.-K.S.; methodology, J.-H.P. and J.-M.L.; project administration, J.-M.L.; writing—original draft, J.-H.P.; writing—review and editing, M.-W.S., H.C.J., J.-K.S., and J.-M.L. All authors have read and agreed to the published version of the manuscript.

Funding: This research received no external funding.

Institutional Review Board Statement: This study was conducted according to the guidelines of the Declaration of Helsinki and approved by the Institutional Review Board of Mahidol University (MU-IRB2014/029.1302).

Informed Consent Statement: Informed consent was obtained from all participants and guardians involved in the study.

Data Availability Statement: The datasets used and/or analyzed during the current study are available from the corresponding author on reasonable request.

Acknowledgments: The authors would like to thank all participants who participated in this study.

Conflicts of Interest: The authors have no conflict of interest to declare.

\section{References}

1. Telama, R.; Yang, X.; Viikari, J.; Välimäki, I.; Wanne, O.; Raitakari, O. Physical activity from childhood to adulthood: A 21-year tracking study. Am. J. Prev. Med. 2005, 28, 267-273. [CrossRef] [PubMed]

2. Mintjens, S.; Menting, M.D.; Daams, J.G.; van Poppel, M.N.M.; Roseboom, T.J.; Gemke, R. Cardiorespiratory Fitness in Childhood and Adolescence Affects Future Cardiovascular Risk Factors: A Systematic Review of Longitudinal Studies. Sports Med. 2018, 48, 2577-2605. [CrossRef]

3. Malina, R.M. Physical activity and fitness: Pathways from childhood to adulthood. Am. J. Hum. Biol. Off. J. Hum. Biol. Counc. 2001, 13, 162-172. [CrossRef]

4. Blair, S.N.; Cheng, Y.; Holder, J.S. Is physical activity or physical fitness more important in defining health benefits? Med. Sci. Sports Exerc. 2001, 33, S379-S399. [CrossRef] [PubMed]

5. Janssen, I.; Leblanc, A.G. Systematic review of the health benefits of physical activity and fitness in school-aged children and youth. Int. J. Behav. Nutr. Phys. Act. 2010, 7, 40. [CrossRef] [PubMed]

6. Ross, R.; Blair, S.N.; Arena, R.; Church, T.S.; Després, J.P.; Franklin, B.A.; Haskell, W.L.; Kaminsky, L.A.; Levine, B.D.; Lavie, C.J.; et al. Importance of Assessing Cardiorespiratory Fitness in Clinical Practice: A Case for Fitness as a Clinical Vital Sign: A Scientific Statement From the American Heart Association. Circulation 2016, 134, e653-e699. [CrossRef]

7. Blasquez Shigaki, G.; Barbosa, C.C.L.; Batista, M.B.; Romanzini, C.L.P.; Gonçalves, E.M.; Junior, H.S.; Ronque, E.R.V. Tracking of health-related physical fitness between childhood and adulthood. Am. J. Hum. Biol. 2020, 32, e23381. [CrossRef]

8. He, Q.Q.; Wong, T.W.; Du, L.; Jiang, Z.Q.; Yu, T.S.; Qiu, H.; Gao, Y.; Liu, W.J.; Wu, J.G. Physical activity, cardiorespiratory fitness, and obesity among Chinese children. Prev. Med. 2011, 52, 109-113. [CrossRef]

9. Eisenmann, J.C.; Welk, G.J.; Ihmels, M.; Dollman, J. Fatness, fitness, and cardiovascular disease risk factors in children and adolescents. Med. Sci. Sports Exerc. 2007, 39, 1251-1256. [CrossRef] [PubMed]

10. Aggio, D.; Smith, L.; Hamer, M. Effects of reallocating time in different activity intensities on health and fitness: A cross sectional study. Int. J. Behav. Nutr. Phys. Act. 2015, 12, 83. [CrossRef]

11. Santos, R.; Mota, J.; Okely, A.D.; Pratt, M.; Moreira, C.; Coelho-e-Silva, M.J.; Vale, S.; Sardinha, L.B. The independent associations of sedentary behaviour and physical activity on cardiorespiratory fitness. Br. J. Sports Med. 2014, 48, 1508-1512. [CrossRef] [PubMed]

12. Collings, P.J.; Westgate, K.; Väistö, J.; Wijndaele, K.; Atkin, A.J.; Haapala, E.A.; Lintu, N.; Laitinen, T.; Ekelund, U.; Brage, S.; et al. Cross-Sectional Associations of Objectively-Measured Physical Activity and Sedentary Time with Body Composition and Cardiorespiratory Fitness in Mid-Childhood: The PANIC Study. Sports Med. (Auckl. N.Z.) 2017, 47, 769-780. [CrossRef] 
13. Júdice, P.B.; Silva, A.M.; Berria, J.; Petroski, E.L.; Ekelund, U.; Sardinha, L.B. Sedentary patterns, physical activity and healthrelated physical fitness in youth: A cross-sectional study. Int. J. Behav. Nutr. Phys. Act. 2017, 14, 25. [CrossRef] [PubMed]

14. Tomkinson, G.R.; Carver, K.D.; Atkinson, F.; Daniell, N.D.; Lewis, L.K.; Fitzgerald, J.S.; Lang, J.J.; Ortega, F.B. European normative values for physical fitness in children and adolescents aged 9-17 years: Results from 2779165 Eurofit performances representing 30 countries. Br. J. Sports Med. 2018, 52, 1445-14563. [CrossRef] [PubMed]

15. Lee, S.; Ko, B.G.; Park, S. Physical Fitness Levels in Korean Adolescents: The National Fitness Award Project. J. Obes. Metab. Syndr. 2017, 26, 61-70. [CrossRef]

16. Kidokoro, T.; Suzuki, K.; Naito, H.; Balasekaran, G.; Song, J.K.; Park, S.Y.; Liou, Y.M.; Lu, D.; Poh, B.K.; Kijboonchoo, K.; et al. Moderate-to-vigorous physical activity attenuates the detrimental effects of television viewing on the cardiorespiratory fitness in Asian adolescents: The Asia-fit study. BMC Public Health 2019, 19, 1737. [CrossRef] [PubMed]

17. Hui, S.S.; Zhang, R. Physical activity and health-related fitness in Asian adolescents: The Asia-fit study. J. Sports Sci. 2020, 38, 273-279. [CrossRef]

18. Lucas, S.R.; Platts-Mills, T.A. Physical activity and exercise in asthma: Relevance to etiology and treatment. J. Allergy Clin. Immunol. 2005, 115, 928-934. [CrossRef] [PubMed]

19. Leinaar, E.; Alamian, A.; Wang, L. A systematic review of the relationship between asthma, overweight, and the effects of physical activity in youth. Ann. Epidemiol. 2016, 26, 504-510. [CrossRef]

20. Almqvist, C.; Li, Q.; Britton, W.J.; Kemp, A.S.; Xuan, W.; Tovey, E.R.; Marks, G.B. Early predictors for developing allergic disease and asthma: Examining separate steps in the 'allergic march'. Clin. Exp. Allergy J. Br. Soc. Allergy Clin. Immunol. 2007, 37, 1296-1302. [CrossRef]

21. Oliveira, T.B.; Persigo, A.L.K.; Ferrazza, C.C.; Ferreira, E.N.N.; Veiga, A.B.G. Prevalence of asthma, allergic rhinitis and pollinosis in a city of Brazil: A monitoring study. Allergol. Immunopathol. 2020, 48, 537-544. [CrossRef]

22. Grossman, J. One airway, one disease. Chest 1997. [CrossRef]

23. Ghiglioni, D.G.; Bruschi, G.; Milani, G.P.; Marchisio, P.G. Vernal allergic march. World Allergy Organ. J. 2021. [CrossRef]

24. Mallol, J.; Crane, J.; von Mutius, E.; Odhiambo, J.; Keil, U.; Stewart, A. The International Study of Asthma and Allergies in Childhood (ISAAC) Phase Three: A global synthesis. Allergol. Immunopathol. 2013, 41, 73-85. [CrossRef] [PubMed]

25. Kuruvilla, M.E.; Vanijcharoenkarn, K.; Shih, J.A.; Lee, F.E. Epidemiology and risk factors for asthma. Respir. Med. 2019, 149, 16-22. [CrossRef] [PubMed]

26. Akinbami, L.J.; Schoendorf, K.C. Trends in childhood asthma: Prevalence, health care utilization, and mortality. Pediatrics 2002, 110, 315-322. [CrossRef]

27. Martinez, F.D. Complexities of the genetics of asthma. Am. J. Respir. Crit. Care Med. 1997, 156, S117-S122. [CrossRef] [PubMed]

28. Steell, L.; Ho, F.K.; Sillars, A.; Petermann-Rocha, F.; Li, H.; Lyall, D.M.; Iliodromiti, S.; Welsh, P.; Anderson, J.; MacKay, D.F.; et al. Dose-response associations of cardiorespiratory fitness with all-cause mortality and incidence and mortality of cancer and cardiovascular and respiratory diseases: The UK Biobank cohort study. Br. J. Sports Med. 2019, 53, 1371-1378. [CrossRef]

29. Lugogo, N.L.; Kraft, M.; Dixon, A.E. Does obesity produce a distinct asthma phenotype? J. Appl. Physiol. 2010, 108, 729-734. [CrossRef] [PubMed]

30. Melén, E.; Granell, R.; Kogevinas, M.; Strachan, D.; Gonzalez, J.R.; Wjst, M.; Jarvis, D.; Ege, M.; Braun-Fahrländer, C.; Genuneit, J.; et al. Genome-wide association study of body mass index in 23000 individuals with and without asthma. Clin. Exp. Allergy 2013, 43, 463-474. [CrossRef]

31. Park, J.H.; Yoo, E. Association between Physical Activity and Respiratory Diseases in Adolescents: An Age- and Gender-Matched Study. Int. J. Environ. Res. Public Health 2021, 18, 1397. [CrossRef]

32. Cooper Institute. FitnessGram administration Manual: The Journey to MyHealthyZone, 5th ed.; Human Kinetics: Champaign, IL, USA, 2017.

33. European Communities. EUROFIT: Handbook for the EUROFIT Tests of Physical Fitness, 2nd ed.; Council of Europe Publishing: Rome, Italy, 1988.

34. Castro-Piñero, J.; Artero, E.G.; España-Romero, V.; Ortega, F.B.; Sjöström, M.; Suni, J.; Ruiz, J.R. Criterion-related validity of field-based fitness tests in youth: A systematic review. Br. J. Sports Med. 2010, 44, 934-943. [CrossRef] [PubMed]

35. Castro-Piñero, J.; Chillón, P.; Ortega, F.B.; Montesinos, J.L.; Sjöström, M.; Ruiz, J.R. Criterion-related validity of sit-and-reach and modified sit-and-reach test for estimating hamstring flexibility in children and adolescents aged 6-17 years. Int. J. Sports Med. 2009, 30, 658-662. [CrossRef] [PubMed]

36. McClain, J.J.; Welk, G.J.; Ihmels, M.; Schaben, J. Comparison of two versions of the PACER aerobic fitness test. J. Phys. Act. Health 2006, 3, S47-S57. [CrossRef]

37. Lee, P.H.; Macfarlane, D.J.; Lam, T.H.; Stewart, S.M. Validity of the International Physical Activity Questionnaire Short Form (IPAQ-SF): A systematic review. Int. J. Behav. Nutr. Phys. Act. 2011, 8, 115. [CrossRef]

38. Hardy, L.L.; Booth, M.L.; Okely, A.D. The reliability of the Adolescent Sedentary Activity Questionnaire (ASAQ). Prev. Med. 2007, 45, 71-74. [CrossRef] [PubMed]

39. McNarry, M.A.; Boddy, L.M.; Stratton, G.S. The relationship between body mass index, aerobic performance and asthma in a pre-pubertal, population-level cohort. Eur. J. Appl. Physiol. 2014, 114, 243-249. [CrossRef] 
40. Wang, Y.; Ghoshal, A.G.; Bin Abdul Muttalif, A.R.; Lin, H.C.; Thanaviratananich, S.; Bagga, S.; Faruqi, R.; Sajjan, S.; Brnabic, A.J.; Dehle, F.C.; et al. Quality of Life and Economic Burden of Respiratory Disease in Asia-Pacific-Asia-Pacific Burden of Respiratory Diseases Study. Value Health Reg. Issues 2016, 9, 72-77. [CrossRef]

41. Joschtel, B.; Gomersall, S.R.; Tweedy, S.; Petsky, H.; Chang, A.B.; Trost, S.G. Effects of exercise training on physical and psychosocial health in children with chronic respiratory disease: A systematic review and meta-analysis. BMJ Open Sport Exerc. Med. 2018, 4. [CrossRef]

42. Winn, C.O.N.; Mackintosh, K.A. Asthma, body mass and aerobic fitness, the relationship in adolescents: The exercise for asthma with commando Joe's ${ }^{\circledR}$ (X4ACJ) trial. J. Sports Sci. 2020, 38, 288-295. [CrossRef]

43. Elmesmari, R.; Reilly, J.J.; Martin, A.; Paton, J.Y. Accelerometer measured levels of moderate-to-vigorous intensity physical activity and sedentary time in children and adolescents with chronic disease: A systematic review and meta-analysis. PLoS ONE 2017, 12. [CrossRef]

44. Sousa, A.W.; Cabral, A.L.B.; Silva, R.A.; Fonseca, A.J.; Grindler, J.; Martins, M.A.; Carvalho, C.R.F. Physical fitness and quality of life in adolescents with asthma and fixed airflow obstruction. Pediatric Pulmonol. 2021, 56, 65-73. [CrossRef] [PubMed]

45. Dixon, A.E.; Peters, U. The effect of obesity on lung function. Expert Rev. Respir. Med. 2018, 12, 755-767. [CrossRef] [PubMed]

46. Behrens, G.; Matthews, C.E.; Moore, S.C.; Hollenbeck, A.R.; Leitzmann, M.F. Body size and physical activity in relation to incidence of chronic obstructive pulmonary disease. Can. Med. Assoc. J. 2014, 186, E457-E469. [CrossRef]

47. Brug, J.; van Stralen, M.M.; Te Velde, S.J.; Chinapaw, M.J.; De Bourdeaudhuij, I.; Lien, N.; Bere, E.; Maskini, V.; Singh, A.S.; Maes, L.; et al. Differences in weight status and energy-balance related behaviors among schoolchildren across Europe: The ENERGY-project. PLoS ONE 2012, 7, e34742. [CrossRef]

48. Small, M.; Piercy, J.; Demoly, P.; Marsden, H. Burden of illness and quality of life in patients being treated for seasonal allergic rhinitis: A cohort survey. Clin. Transl. Allergy 2013, 3, 33. [CrossRef] [PubMed]

49. Canonica, G.W.; Bousquet, J.; Mullol, J.; Scadding, G.K.; Virchow, J.C. A survey of the burden of allergic rhinitis in Europe. Allergy 2007, 62, 17-25. [CrossRef]

50. Blaiss, M.S.; Hammerby, E.; Robinson, S.; Kennedy-Martin, T.; Buchs, S. The burden of allergic rhinitis and allergic rhinoconjunctivitis on adolescents: A literature review. Ann. Allergy Asthma Immunol. 2018, 121, 43-52. [CrossRef] [PubMed]

51. Ruiz, J.R.; Ortega, F.B.; Rizzo, N.; Villa, I.; Hurtig-Wennlöf, A.; Oja, L.; Sjöström, M. High cardiovascular fitness is associated with low metabolic risk score in children: The European Youth Heart Study. Pediatric Res. 2007, 61, 350-355. [CrossRef]

52. Hurtig-Wennlöf, A.; Ruiz, J.R.; Harro, M.; Sjöström, M. Cardiorespiratory fitness relates more strongly than physical activity to cardiovascular disease risk factors in healthy children and adolescents: The European Youth Heart Study. Eur. J. Cardiovasc. Prev. Rehabil. 2007, 14, 575-581. [CrossRef]

53. Ruiz, J.R.; Sui, X.; Lobelo, F.; Morrow, J.R., Jr.; Jackson, A.W.; Sjöström, M.; Blair, S.N. Association between muscular strength and mortality in men: Prospective cohort study. BMJ 2008, 337. [CrossRef]

54. Ruiz, J.R.; Sui, X.; Lobelo, F.; Lee, D.C.; Morrow, J.R., Jr.; Jackson, A.W.; Hébert, J.R.; Matthews, C.E.; Sjöström, M.; Blair, S.N. Muscular strength and adiposity as predictors of adulthood cancer mortality in men. Cancer Epidemiol. Biomark. Prev. 2009, 18, 1468-1476. [CrossRef] [PubMed]

55. Silventoinen, K.; Magnusson, P.K.; Tynelius, P.; Batty, G.D.; Rasmussen, F. Association of body size and muscle strength with incidence of coronary heart disease and cerebrovascular diseases: A population-based cohort study of one million Swedish men. Int. J. Epidemiol. 2009, 38, 110-118. [CrossRef] [PubMed]

56. Latorre-Román, P.; Navarro-Martínez, A.V.; Mañas-Bastidas, A.; García-Pinillos, F. Handgrip strength test as a complementary tool in monitoring asthma in daily clinical practice in children. Iran J. Allergy Asthma Immunol. 2014, 13, $396-403$.

57. Becque, M.D.; Katch, V.L.; Rocchini, A.P.; Marks, C.R.; Moorehead, C. Coronary risk incidence of obese adolescents: Reduction by exercise plus diet intervention. Pediatrics 1988, 81, 605-612. [PubMed] 